\title{
Menu Evaluation of Meal Boxes Sold in Korean Convenience Stores
}

\author{
Jeongyun Choi ${ }^{1}$, Haeryun Park ${ }^{1}$, Kyunghee Song ${ }^{1}$, Sooyoun Kwon ${ }^{2}$, Youngmi Lee ${ }^{1, *}$ \\ ${ }^{1}$ Department of Food and Nutrition, Myongii University, Gyeonggi, South Korea \\ ${ }^{2}$ Department of Food and Nutrition, Shingu University, Gyeonggi, South Korea \\ *Corresponding author: zeromi@mju.ac.kr
}

\begin{abstract}
Despite rapid growth in the meal box market, few studies have examined the dietary quality of convenience store meal boxes. This study aimed to evaluate nutritional quality of meal boxes sold in Korean convenience stores, to determine whether they are appropriate as a single complete meal for Korean adults. A total of 46 meal boxes from four major convenience stores were collected and menu composition as well as food diversity was analyzed. Calorie and nutrient content were compared to one-third of the recommended daily Korean Dietary Reference Intakes in men aged between 19 and 29 years. Stir-fried, grilled, and deep-fried food was provided in larger portions, whereas fruit and dairy product servings were limited. The dietary variety score was only 3.2. The grain, meat, vegetables, fruit, and dairy patterns of 43 among the 46 meal boxes were a ' 11100 '. The amount of meat provided exceeded the one-third of the daily recommended serving sizes for 19-29 aged Korean men by $136 \%$, whereas that of vegetables was only $36 \%$. The average calorie amount was $82.8 \%$ of estimated energy requirements, and sodium content was $242.4 \%$ of adequate intake. It was concluded that lack of food diversity and unbalanced nutrition was a common issue regardless of meal box type. Convenience store meal boxes that meet consumer nutritional needs should be developed to provide appropriate nutrition within a single complete meal.
\end{abstract}

Keywords: meal box, convenience store, menu, food diversity, dietary quality

Cite This Article: Jeongyun Choi, Haeryun Park, Kyunghee Song, Sooyoun Kwon, and Youngmi Lee, "Menu Evaluation of Meal Boxes Sold in Korean Convenience Stores." Journal of Food and Nutrition Research, vol. 6, no. 1 (2018): 18-25. doi: 10.12691/jfnr-6-1-4.

\section{Introduction}

An increase in single-person households and a shift to a convenience-oriented lifestyle, due to economic and socio-cultural changes, have led to a rapid change in Korean consumers' eating habits. Accordingly, the number of consumers eating supermarket-purchased meals at home is increasing. A meal eaten at home but purchased elsewhere is classified as a home meal replacement [1] or as a 'middle-meal', since it falls between a home cooked meal (inner meal) and a restaurant prepared meal (outer meal) [2]. The most representative type of middle-meal is a meal box purchased outside the home.

The Korean meal box market has expanded with consumer demand for quicker and more convenient food, and this growth is expected to continue. As the meal box business gained recognition as a promising industry, many foodservice companies including restaurants and convenience stores, which had not previously produced or sold meal boxes, were prompted to participate in the meal box business. Meal boxes sold in convenience stores have since shown the biggest sales growth [3].

A convenience store is a small store or shop that generally sells daily necessities including convenience food, sweets, and soft drinks. This model was created to ensure easy access, direct service, and the possibility of frequent visits [4]. In recent years within South Korea, the convenience store market has continued to expand rapidly compared to other nations. The number of convenience stores nationwide reached approximately 31,500 in 2015 [5]. In the same year, the convenience store market registered a growth of $9.4 \%$ compared to the previous year, with a particularly high rate of growth in private brand (PB) products. The sales of PB products in one Korean convenience store company reached $35.9 \%$ of its total sales [6]. Among various PB products sold in convenience stores, meals boxes showed the highest rate of growth, and therefore, the convenience store industry is focusing on developing competitive PB meal box products. The domestic market size of convenience store meal boxes in Korea exceeded 300 billion won in 2015, and the sale of these meal boxes by three big convenience store companies had increased by $50 \%$ compared to the previous year [7].

In a previous study on the purchase behavior of convenience store meal box users and their awareness of convenience store meal boxes, undertaken with 1,000 Korean consumers aged between 19 and 59 years, $78.6 \%$ of the respondents answered that they had consumed meal boxes within the previous three months and $71.5 \%$ of them had purchased meal boxes at convenience stores [8]. Consumers perceived convenience store meal boxes as convenient, "not bad to try once," and adequate for a meal [8], but taste and healthiness scored relatively low 
$[9,10,11]$. Nonetheless, as meal boxes become more attractive for today's busy consumers, the number of people purchasing meal boxes at convenience stores as meal replacements is expected to increase steadily. On the other hand, as more consumers considered food quality as an important factor when making a purchase, there has been a rapid growth in the sales of meal boxes that were more expensive over the last few years [12].

Despite the rapid growth in the convenience store meal box market, providing nutritional information on the meal boxes is not a legal requirement in South Korea [13]. Some meal boxes do provide nutritional information; however, the information is limited and not easy to understand, which makes it difficult for consumers to choose nutritionally suitable meal boxes. In addition, meal boxes on sale were nutritionally unbalanced, with menus containing relatively high portions of meat or processed foods. A previous research study investigating the nutritional values of eight different types of meal boxes sold in convenience stores revealed that the portion sizes for meat items were too big while those of vegetables were relatively small, which could lead to excessive meat consumption. Additionally, the high sodium content of the meal boxes was found to be significant [14]. In another study evaluating the nutritional quality of convenience store meal boxes purchased by low-income children who were supported by the Korean government-funded meal support program, the amount of vitamin $A$, vitamin $C$, and calcium were found to be deficient compared to one-third of recommended daily intake for 9 to 11 year-old boys [15].

The main consumers of convenience store meal boxes mainly comprised people who did not eat regular and balanced meals, who usually ate meals alone, and who were aged between 20 and 40 years of age, unmarried, and unemployed $[8,16,17,18]$. However, few studies have examined the nutritional quality of convenience store meal boxes. Therefore, this study aimed to evaluate the dietary quality of the meal boxes sold at Korean convenience stores. We attempted to determine whether meal boxes are nutritionally appropriate and sufficient to serve as one complete meal for Korean adults. Specifically, the differences according to meal box types and prices were analyzed, as these two factors become more diverse.

\section{Materials and Methods}

\subsection{Research Materials}

There are six franchise convenience store brands in South Korea. Of these, four major convenience store brands, which had more than 1,000 stores nationwide in March 2016, were included in the research for data collection. The market share of these four convenience store companies by store numbers was more than $95 \%$ in 2015 [5]. We purchased all the meal boxes for our study, in sales on September 2016, from the four convenience store brands and analyzed them. The list of meal boxes on sale at each convenience store brand was provided from each company. A total of 46 meal boxes were collected from convenience stores located in Yongin city. Each meal box was produced in a production facility as per the standard recipe issued from the company headquarter, such that identical meal boxes sold in any convenience store contained the same menu.

In this study, a meal box was defined as 'a meal provided in a container with a combination of staple food and side dishes'. Therefore, other types of meal replacement sold in convenience stores, such as gimbap (Korean dish made form cooked rice and various other ingredients, and rolled in dried seaweed), sandwiches, hamburgers, and salads, were not included in this study.

We categorized the meal boxes into two types, namely rice plus side dish (traditional Korean meal structure) or one-dish, according to the meal type combining staple food and side dishes included in the meal boxes. For example, meals such as bibimbap (mixed rice with meat and assorted vegetables) and deopbap (rice with toppings) were categorized as one-dish. In addition, the meal boxes were categorized based on the price. According to the average price of the meal boxes being evaluated, equivalent to 3,857 won, the meal boxes were divided into two groups: $<3,900$ won and $\geq 3,900$ won.

\subsection{Menu Composition}

To analysis menu patterns of meal boxes, the menu items included in the meal boxes were divided into 16 food types based on the Korean cooking methods used for preparation [19]. The inclusion frequency and the amounts provided for each food group were analyzed. To calculate the amounts of each food provided for each category, the weight of each menu item was measured to $0.1 \mathrm{~g}$, using a digital weight.

\subsection{Food Diversity}

The diversity of menus included in the meal boxes was evaluated according to analysis of the total number of menu items, the dietary variety score (DVS), food group pattern (grains, meat, vegetables, fruit, and dairy [GMVFD] pattern), dietary diversity score (DDS), providing amount of each food group. The total number of menu items was calculated by counting the number of menu items included in the meal boxes, with the exception of sauces and condiments. The DVS was calculated by counting the number of ingredients of the foods included in the meal boxes, excluding sauces and condiments. To calculate the DVS, foods whose weights did not satisfy threshold amounts were excluded [20].

The GMVFD pattern analyzed five basic food groups, namely grains, meats, vegetables, fruits, and milk and dairy products. The meat group included meat, fish, and eggs, and the vegetable group included both raw and cooked vegetables, as well as mushrooms and seaweeds. If a food equivalent in each food group was included in the meal box, it was marked as "1," otherwise it was marked as " 0 " [20]. The DDS were calculated by allocating 1 point to each of the five food groups provided in the meal boxes. The highest possible score is 5 points, when all 5 food groups are provided. When analyzing the GMVFD pattern and the DDS, the minimum threshold amounts of foods [20] were considered. 


\subsection{Calorie and Nutrient Contents}

We analyzed the calorie contents of 41 meal boxes, identified with information included in the meal box. Additionally, the nutrient content of a total of 28 meal boxes out of 41, which included additional information concerning eight nutrients (carbohydrate, sugar, protein, fat, saturated fat, trans fatty acids, cholesterol, and sodium) were analyzed. The calorie content was compared with one-third of the estimated energy requirements of men aged between 19 and 29 years, and the nutrient contents were compared with one-third of Dietary Reference Intakes for Koreans (KDRIs) [21] of men aged between 19 and 29 years.

\subsection{Statistical Analysis}

All data were analyzed using Excel 2010 and the SPSS 23.0 statistical package. The frequency and percentage, or average and standard deviation values were presented, according to the type of data analyzed. The differences in the distribution were analyzed using the Fisher' exact test, and Student's t-test was used to determine the differences in the average values. The data were compared and analyzed according to the type and price of meal box. All measured values were verified with a statistical significance of $\mathrm{p}<0.05$.

\section{Results}

\subsection{General Characteristics}

The general characteristics of the meal boxes evaluated are shown in Table 1. The rice plus side dish meal boxes comprised $78.3 \%$, and one-dish meal boxes comprised $21.7 \%$. The average price was 3,857 won, ranging from 3,000 to 4,900 won. Meal boxes costing under 3,900 won comprised $39.1 \%$ and $60.9 \%$ of meal boxes cost more than 3,900 won. The average price of a rice plus side dish meal box was 3,967 won and that of a one-dish meal box was 3,460 won $(\mathrm{p}=0.001)$

The majority of meal boxes, 41 of the 46, were provided with calorie information on the packaging, but only 28 meal boxes among them were provided with additional information concerning another 8 nutrients besides calories (carbohydrate, sugar, protein, fat, saturated fat, trans fatty acids, cholesterol, and sodium).

Table 1. General Characteristics of the Meal Boxes

\begin{tabular}{|l|c|}
\hline \multicolumn{1}{|c|}{ Characteristics } & Total $(\mathrm{n}=46)$ \\
\hline Type & $36(78.3)^{1)}$ \\
\hline Rice plus side dish & $10(21.7)$ \\
\hline One-dish & $18(39.1)$ \\
\hline Price & $28(60.9)$ \\
\hline$<3,900$ & $3,856.5 \pm 433.9^{2)}$ \\
\hline$\geq 3,900$ & \\
\hline Mean & $13(28.3)$ \\
\hline Provision of nutrition labeling & $28(60.9)$ \\
\hline Only calorie & \\
\hline Calorie + nutrients ${ }^{3)}$ & \\
\hline
\end{tabular}

${ }^{1)} \mathrm{n}(\%),{ }^{2)}$ mean $\pm \mathrm{SD},{ }^{3)}$ Carbohydrate, sugar, protein, fat, saturated fat, trans fatty acid, cholesterol, and sodium

\subsection{Menu Composition}

The food type frequencies according to meal box type and price are shown in Table 2. Rice was included in all the meal boxes. Among side dishes, stir-fried food was included most frequently, in $93.5 \%$ of meal boxes, followed by grilled food $(65.2 \%)$ and deep-fried food $(50.0 \%)$. Fruit was included in only one meal box, and milk and dairy product were provided in only 3 of 46 meal boxes.

The inclusion frequency of stir-fried food was the highest, irrespective of meal box type: $94.4 \%$ in rice plus side dish meal boxes and $90.9 \%$ in one-dish meal boxes. There was a significant difference in the inclusion frequency of deep-fried food according to meal box type ( $p=0.010$ ), with $61.1 \%$ of rice plus side dish meal boxes providing deep-fried side dishes but only one inclusion of deep-fried food in the one-dish type meal boxes $(10.0 \%)$. The inclusion frequency of deep-fried food showed a significant difference according to the price of meal boxes. There were only $27.8 \%$ of meal boxes containing deepfried food among meal boxes costing less than 3,900 won, but $64.3 \%$ of meal boxes costing more than 3,900 won provided a deep-fried side dish $(\mathrm{p}=0.033)$.

In addition, the meal boxes containing stir-fried, grilled, and deep-fried food on their menus provided on average $3.1,1.7$, and 1.5 equivalent menu items, respectively. Although stir-fried vegetables were frequently provided in stir-fried menus, majority of the grilled and deep-fried menus were primarily meat based, including grilled sausages, fried chicken and pork cutlet.

The amounts of food provided for each category are presented in Table 3. The average amount of rice and grain provided was the largest, equivalent to $199.9 \mathrm{~g}$, followed by stir-fried food $(82.8 \mathrm{~g})$, grilled food (43.4 g), and deep-fried food $(36.0 \mathrm{~g})$. On the other hand, the average amount of milk and dairy products, and fruit, amounted to only $0.1 \mathrm{~g}$ and $0.4 \mathrm{~g}$, respectively. Stir-fried $(83.5 \mathrm{~g})$, grilled (48.9 g), and deep-fried food (44.3 g) were provided in larger portions in the rice plus side dish meal boxes, whereas in the one-dish meal boxes, stir-fried food (80.3 g), soup and stew (26.5 g), and namul (Korean seasoned vegetable dish) and salad (26.2 g) were provided in larger portions. Meal boxes costing less than 3,900 won contained stir-fried (81.9 g), grilled food (33.2 g), and namul and salad $(21.5 \mathrm{~g})$ in larger portions, whereas, meal boxes costing 3,900 won or more contained stir-fried $(83.3 \%)$, grilled $(50.0 \mathrm{~g})$, and deep-fried food (48.6 $\mathrm{g})$ in larger portions.

There was a significant difference in the amounts of rice $(p=0.011)$, soup and stew $(p=0.008)$, deep-fried food $(p=0.034)$, and sauce and condiment $(p=0.019)$, according to the meal box type. Rice, as well as soup and stew, were provided in greater quantities in the one-dish meal boxes than in the rice plus side dish meal boxes. However, the amount of deep-fried food provided was considerably more in the rice plus side dish meal boxes $(44.3 \mathrm{~g})$ than in the one-dish meal boxes $(6.0 \mathrm{~g})$. According to price, noodles $(p=0.027)$ and deep-fried foods $(p=0.018)$ showed significant differences. Deepfried food was provided in considerably greater quantities in the meal boxes costing more than 3,900 won (48.6 g) than in the meal boxes costing less than 3,900 won (16.4 g). 


\subsection{Food Diversity}

Table 4 shows the total number of menu items and the DVS. Overall, meal boxes comprising 7 menu items on average and meal boxes containing between 6 to 10 menu items were the most common $(69.6 \%)$. The rice plus side dish meal boxes averaged 7.7 menu items compared to the one-dish meal boxes, which averaged 4.5 menu items, showing a significant difference $(p=0.012)$. The total number of menu items was also significantly different according to the price ( $\mathrm{p}=0.002$ ): 5.9 on average in the meal boxes costing less than 3,900 won and 7.7 on average in the meal boxes costing more than 3,900 won.

The DVS of the rice plus side meal boxes (3.3) tended to be higher than that of the one dish type meal boxes (2.6) $(\mathrm{p}=0.062)$. However, there was no significant difference according to the price in the DVS.

Table 2. Inclusion Frequency of Food Types in the Meal Boxes

\begin{tabular}{|c|c|c|c|c|c|c|c|}
\hline \multirow{2}{*}{ Food group } & \multirow{2}{*}{$\begin{array}{c}\text { Total } \\
(\mathrm{n}=46)\end{array}$} & \multicolumn{3}{|c|}{ Meal type } & \multicolumn{4}{|c|}{ Price } \\
\cline { 3 - 7 } & & Rice plus side dish $(\mathrm{n}=36)$ & $\begin{array}{c}\text { One-dish } \\
(\mathrm{n}=10)\end{array}$ & $\mathrm{p})$ & $\begin{array}{c}<3,900 \\
(\mathrm{n}=18)\end{array}$ & $\begin{array}{c}\geq 3,900 \\
(\mathrm{n}=28)\end{array}$ & $\mathrm{p}$ \\
\hline Rice & $46(100)^{1)}$ & $36(100)$ & $10(100)$ & - & $18(100)$ & $18(100)$ & - \\
\hline Bread & $1(2.2)$ & $1(2.8)$ & $0(0)$ & 1.000 & $1(5.6)$ & $0(0)$ & 0.391 \\
\hline Noodle & $5(10.9)$ & $5(13.9)$ & $0(0)$ & 0.570 & $0(0)$ & $5(17.9)$ & 0.140 \\
\hline Stew & $2(4.3)$ & $0(0)$ & $2(20.0)$ & 0.043 & $1(5.6)$ & $1(3.6)$ & 1.000 \\
\hline Steamed & $3(6.5)$ & $3(8.3)$ & $0(0)$ & 1.000 & $2(11.1)$ & $1(3.6)$ & 0.552 \\
\hline Grilled & $30(65.2)$ & $25(69.4)$ & $5(50.0)$ & 0.283 & $10(55.6)$ & $20(71.4)$ & 0.347 \\
\hline Jeon ${ }^{3)}$ & $8(17.4)$ & $5(13.9)$ & $3(30.0)$ & 0.344 & $3(16.7)$ & $5(17.9)$ & 1.000 \\
\hline Stir fried & $43(93.5)$ & $34(94.4)$ & $9(90.0)$ & 0.530 & $16(88.9)$ & $27(96.4)$ & 0.552 \\
\hline Jorim ${ }^{4}$ & $10(21.7)$ & $9(25.0)$ & $1(10.0)$ & 0.420 & $3(16.7)$ & $7(25.0)$ & 0.717 \\
\hline Deep fried & $23(50.0)$ & $22(61.1)$ & $1(10.0)$ & 0.010 & $5(27.8)$ & $18(64.3)$ & 0.033 \\
\hline Namul $)^{5}$ and salad & $16(34.8)$ & $14(38.9)$ & $2(20.0)$ & 0.455 & $6(33.3)$ & $10(35.7)$ & 1.000 \\
\hline Pickle & $5(10.9)$ & $3(8.3)$ & $2(20.0)$ & 0.295 & $2(11.1)$ & $3(10.7)$ & 1.000 \\
\hline Sauce and condiment & $12(26.1)$ & $8(22.2)$ & $4(40.0)$ & 0.416 & $5(27.8)$ & $7(25.0)$ & 1.000 \\
\hline Milk and dairy product & $1(2.2)$ & $0(0)$ & $1(10.0)$ & 0.217 & $1(5.6)$ & $0(0)$ & 0.391 \\
\hline Fruit & $3(6.5)$ & $2(5.6)$ & $1(10.0)$ & 0.615 & $1(5.6)$ & $2(7.1)$ & 0.831 \\
\hline Others & $5(10.9)$ & $4(11.1)$ & $1(10.0)$ & 1.000 & $3(16.7)$ & $2(7.1)$ & 0.365 \\
\hline
\end{tabular}

${ }^{1)} \mathrm{n}(\%),{ }^{2)} \mathrm{p}$ value using Fisher's exact test, ${ }^{3)}$ pancake-like Korean dish, ${ }^{4)}$ simmered Korean dish, ${ }^{5)}$ Korean seasoned vegetable dish

Table 3. Amounts of Food Provided for each Food Type in the Meal Boxes (g)

\begin{tabular}{|c|c|c|c|c|c|c|c|}
\hline \multirow[b]{2}{*}{ Food type } & \multirow{2}{*}{$\begin{array}{c}\text { Total } \\
(\mathrm{n}=46)\end{array}$} & \multicolumn{3}{|c|}{ Meal type } & \multicolumn{3}{|c|}{ Price } \\
\hline & & $\begin{array}{l}\text { Rice plus side dish } \\
\quad(\mathrm{n}=36)\end{array}$ & $\begin{array}{c}\text { One-dish } \\
(\mathrm{n}=10)\end{array}$ & $\mathrm{p}^{2)}$ & $\begin{array}{l}<3,900 \\
(\mathrm{n}=18)\end{array}$ & $\begin{array}{l}\geq 3,900 \\
(\mathrm{n}=28)\end{array}$ & $\mathrm{p}$ \\
\hline Rice & $199.9 \pm 35.3^{1)}$ & $192.2 \pm 32.3$ & $227.1 \pm 33.3$ & 0.011 & $203.5 \pm 51.1$ & $197.3 \pm 20.4$ & 0.567 \\
\hline Bread & $0.3 \pm 2.0$ & $0.4 \pm 2.3$ & 0.0 & 0.604 & $0.8 \pm 3.3$ & 0.0 & 0.331 \\
\hline Noodle & $6.2 \pm 18.5$ & $7.9 \pm 20.6$ & 0.0 & 0.236 & 0.0 & $10.2 \pm 23.0$ & 0.027 \\
\hline Stew & $5.8 \pm 28.6$ & 0.0 & $26.5 \pm 58.9$ & 0.008 & $9.6 \pm 40.5$ & $3.3 \pm 17.6$ & 0.477 \\
\hline Steamed & $3.5 \pm 15.4$ & $4.5 \pm 17.3$ & 0.0 & 0.422 & $7.5 \pm 23.7$ & $0.9 \pm 4.9$ & 0.259 \\
\hline Grilled & $43.4 \pm 41.8$ & $48.9 \pm 44.1$ & $23.7 \pm 24.5$ & 0.091 & $33.2 \pm 35.5$ & $50.0 \pm 44.7$ & 0.186 \\
\hline Jeon $^{3)}$ & $1.5 \pm 5.1$ & $1.2 \pm 4.9$ & $2.8 \pm 5.7$ & 0.373 & $0.7 \pm 2.6$ & $2.1 \pm 6.1$ & 0.374 \\
\hline Stir fried & $82.8 \pm 54.7$ & $83.5 \pm 57.0$ & $80.3 \pm 48.4$ & 0.861 & $81.9 \pm 51.1$ & $83.3 \pm 57.9$ & 0.932 \\
\hline Jorim $^{4)}$ & $11.5 \pm 29.9$ & $13.9 \pm 33.2$ & $2.9 \pm 9.0$ & 0.307 & $7.4 \pm 24.0$ & $14.1 \pm 33.3$ & 0.466 \\
\hline Deep fried & $36.0 \pm 51.0$ & $44.3 \pm 54.1$ & $6.0 \pm 18.8$ & 0.034 & $16.4 \pm 30.0$ & $48.6 \pm 57.9$ & 0.018 \\
\hline Namul $l^{5}$ and salad & $20.0 \pm 41.4$ & $18.2 \pm 38.3$ & $26.2 \pm 56.8$ & 0.603 & $21.5 \pm 43.4$ & $19.0 \pm 42.5$ & 0.845 \\
\hline Pickle & $1.4 \pm 4.2$ & $1.2 \pm 4.1$ & $2.1 \pm 4.5$ & 0.574 & $1.4 \pm 4.6$ & $1.3 \pm 4.0$ & 0.901 \\
\hline Sauce and condiment & $8.2 \pm 18.4$ & $4.9 \pm 11.5$ & $20.1 \pm 31.3$ & 0.019 & $12.4 \pm 25.0$ & $5.6 \pm 12.4$ & 0.293 \\
\hline Milk and dairy product & $0.1 \pm 0.8$ & 0.0 & $0.6 \pm 1.7$ & 0.057 & $0.3 \pm 1.3$ & 0.0 & 0.331 \\
\hline Fruit & $0.4 \pm 2.5$ & $0.5 \pm 2.9$ & 0.0 & 0.604 & $1.0 \pm 4.0$ & 0.0 & 0.331 \\
\hline Others & $6.4 \pm 26.7$ & $8.1 \pm 30.0$ & 0.0 & 0.400 & $14.2 \pm 41.6$ & $1.4 \pm 5.4$ & 0.211 \\
\hline
\end{tabular}

${ }^{1)}$ mean $\pm \mathrm{SD},{ }^{2)}$ p value using Student's t-test, ${ }^{3)}$ pancake-like Korean dish, ${ }^{4)}$ simmered Korean dish, ${ }^{5}$ Korean seasoned vegetable dish 
Table 4. Number of Menu Items and DVS of the Meal Boxes

\begin{tabular}{|c|c|c|c|c|c|c|c|}
\hline \multirow[b]{2}{*}{ Classification } & \multirow{2}{*}{$\begin{array}{c}\text { Total } \\
(n=46)\end{array}$} & \multicolumn{3}{|c|}{ Meal type } & \multicolumn{3}{|c|}{ Price } \\
\hline & & $\begin{array}{l}\text { Rice plus side dish } \\
\qquad(\mathrm{n}=36)\end{array}$ & $\begin{array}{l}\text { One-dish } \\
(\mathrm{n}=10)\end{array}$ & $\mathrm{p}^{4)}$ & $\begin{array}{l}<3,900 \\
(n=18)\end{array}$ & $\begin{array}{l}\geq 3,900 \\
(\mathrm{n}=28)\end{array}$ & $\mathrm{p}$ \\
\hline \multicolumn{8}{|c|}{ No. of menu items } \\
\hline $1-5$ & $10(21.7)^{2)}$ & $4(11.1)$ & $6(60.0)$ & \multirow{3}{*}{0.008} & $5(27.8)$ & $5(17.9)$ & \multirow{3}{*}{0.707} \\
\hline $6-10$ & $32(69.6)$ & $28(77.8)$ & $4(40.0)$ & & $12(66.7)$ & $20(71.4)$ & \\
\hline $11-15$ & $4(8.7)$ & $4(11.1)$ & $0(0)$ & & $1(5.6)$ & $3(10.7)$ & \\
\hline Mean & $7.0 \pm 2.6^{3)}$ & $7.7 \pm 2.0$ & $4.5 \pm 3.2$ & 0.012 & $5.9 \pm 3.0$ & $7.7 \pm 2.0$ & 0.002 \\
\hline \multicolumn{8}{|l|}{$\mathrm{DVS}^{1)}$} \\
\hline $1-3$ & $30(65.2)$ & $22(61.1)$ & $14(38.9)$ & \multirow{2}{*}{0.455} & $13(72.2)$ & $5(27.8)$ & \multirow{2}{*}{0.533} \\
\hline $4-6$ & $16(34.8)$ & $8(80.0)$ & $2(20.0)$ & & $5(27.8)$ & $11(39.3)$ & \\
\hline Mean & $3.2 \pm 1.1$ & $3.3 \pm 1.1$ & $2.6 \pm 1.1$ & 0.062 & $2.9 \pm 1.3$ & $3.3 \pm 0.9$ & 0.262 \\
\hline
\end{tabular}

${ }^{1)}$ dietary variety score, ${ }^{2)} \mathrm{n}(\%),{ }^{3)}$ mean $\pm \mathrm{SD},{ }^{4)} \mathrm{p}$ value by Student's t-test or Fisher's exact test

The GMVFD patterns and the DDS are presented in Table 5. Among the 46 meal boxes surveyed, 43 meal boxes recorded a ' 11100 ' pattern $(93.5 \%)$, meaning the inclusion of only three food groups: grain, meat, and vegetable. The three other meal boxes consisted only of grain and meat, giving a '11000' pattern. Any significant differences in the GMVFD patterns were reported according to the type and price of the meal boxes. The DDS was 3.0 points on average. Comparison of the DDS according to the type and price of the meal boxes did not reveal any significant differences, with 2.9 points for all types.

Table 6 shows the provided amounts of each food group. The Korean Dietary Reference recommends 2,400B daily dietary pattern for men aged 19-29 years (4 servings of grain, 5 servings of meat, 8 servings of vegetables, 3 servings of fruits, and 1 serving of milk and dairy products) [21]. When compared to one-third of the recommended servings for each food group, the amounts of grain, meat, and vegetable provided by meal boxes were equivalent to $76 \%, 136 \%$, and $36 \%$, respectively. The serving size of fruits and dairy products were negligible. The serving size of meat was significantly larger in rice plus side dish meal boxes than in one-dish meal boxes $(\mathrm{p}<0.001)$ as well as in the meal boxes costing more than 3,900 won when compared to those less than 3,900 won $(p=0.026)$.

\subsection{Calorie and nutrient contents}

Table 7 shows the calorie and nutritional content of the meal boxes, derived from nutritional information provided on the packaging, and the comparison of this information with one-third of the daily KDRIs of men aged from 19 to 29 years. The average calorie content was $717.2 \mathrm{kcal}$, corresponding to $82.8 \%$ of the daily estimated energy requirements of 19 to 29 -year-old men. There was no significant difference in calorie content according to the type of meal boxes, but the calorie content of meal boxes costing more than 3,900 won $(772.2 \mathrm{kcal})$ was significantly higher than that of meal boxes costing less than 3,900 won $(639.6 \mathrm{kcal})(\mathrm{p}=0.008)$.

The average energy contribution of carbohydrate $(59.4 \%)$, protein $(15.0 \%)$, and sugar $(4.8 \%)$ were within the guidelines of the KDRIs, but fat slightly exceeded the guideline, with $30.6 \%$. The average energy contribution of saturated fat $(7.5 \%)$ also exceeded the guideline.

The energy contribution ratios of nutrients did not show any significant differences according to the type of meal boxes. However, the energy contribution of carbohydrate was significantly lower $(\mathrm{p}=0.030)$, and that of protein were significantly higher $(p=0.008)$ in meal boxes costing more than 3,900 won than in meal boxes costing less than 3,900 won. In addition, the energy contribution of saturated fat tended to be higher in the meal boxes which costing more than 3,900 won $(\mathrm{p}=0.076)$.

The average protein content was $21.7 \mathrm{~g}$, corresponding to $119.7 \%$ of the one-third daily recommended intake. The average sodium content was 1,211 mg, 242.4\% of adequate intake (AI), and the average cholesterol content also exceeded the daily recommended intake at $114 \%$. No significant differences were observed in protein, cholesterol, and sodium content according to the type and price of the meal boxes.

\section{Discussion}

This study aimed to evaluate whether the meal boxes sold in the Korean main convenience stores were appropriate as one complete meal for Korean adults. The study results revealed problems yet to be resolved, to ensure healthier diet for adults frequently consuming convenience store meal boxes as a single daily meal.

It is noteworthy that stir-fried or deep-fried food was included frequently and in a relatively higher portion, whereas namul and salad, which is the representative vegetable menu, as well as fruit, and milk and dairy products, were found to be lacking in all meal box types. Only 3 meal boxes contained fruit and only 1 meal box contained dairy products out of 46 meal boxes under study. Furthermore, the higher the price of meal box, the more often deep-fried food cooked mainly with meat products was served. Interestingly, all kimchi (Korean salted and fermented vegetables) products included in the meal boxes were stir-fried. Stir-frying was the cooking method used most frequently in the meal boxes included in our study. The most likely explanation is that stir-frying is an effective cooking method to reduce hygiene risks during the production or distribution process [22]. However, it is 
necessary to develop menus to replace stir-fried or deepfried food, because these are cooking techniques using excessive oil.

We also found problems in relation to food diversity in meal boxes. The average DVS was only 3.2 , without showing any differences according to the type and price of meal boxes, which means that food diversity was very low in almost all of meal boxes sold in convenience stores. Recently, the sales of convenience store meal boxes that were relatively more expensive have increased [12]. However, our study showed that a higher price did not guarantee food variety in the more expensive meal boxes.

Low food variety was also verified according to the results of the GMVFD pattern and the DDS analysis. The majority of meal boxes showed a ' 11100 ' pattern. Moreover, most of the ' 11100 ' pattern meal boxes contained stir-fried kimchi, the amount of which was usually $30 \mathrm{~g}$. Therefore, if stir-fried kimchi was excluded, the amounts of vegetables did not reach the minimum amounts, corresponding to $30 \mathrm{~g}$ [20].

The lack of food diversity was a problem regardless of the type and price of the meal boxes, with a concentration in grain and protein foods, and a lack of various side dishes comprising vegetables, fruits, and milk and dairy products. The provided amount of meat exceeded the one-third of the daily recommended serving sizes for 19-29 aged Korean men by $136 \%$; whereas, that of vegetables was only $36 \%$. This trend was more distinct in the rice plus side dish meal boxes and those costing more than 3,900 won. A previous study has highlighted that the amount of meat is too much and the amount of vegetables insufficient in convenience store meal boxes [14]. The results of this study revealed that there has yet to be an improvement. It is difficult to include fruits and dairy products in meal boxes as menu items when considering the standard Korean meal. Therefore, it is necessary to encourage consumers of meal boxes to supplement their daily snacks with fruits and dairy products.

Table 5. GMVFD Pattern and DDS of the Meal Boxes

\begin{tabular}{|c|c|c|c|c|c|c|c|}
\hline \multirow[b]{2}{*}{ Classification } & \multirow[b]{2}{*}{ Total } & \multicolumn{3}{|c|}{ Meal type } & \multicolumn{3}{|c|}{ Price } \\
\hline & & $\begin{array}{l}\text { Rice plus side dish } \\
\quad(\mathrm{n}=36)\end{array}$ & $\begin{array}{l}\text { One-dish } \\
(\mathrm{n}=10)\end{array}$ & $\mathrm{p}^{5)}$ & $\begin{array}{l}<3,900 \\
(\mathrm{n}=18)\end{array}$ & $\begin{array}{l}\geq 3,900 \\
(\mathrm{n}=28)\end{array}$ & $\mathrm{p}$ \\
\hline \multicolumn{8}{|l|}{ GMVFD pattern $^{1)}$} \\
\hline 11100 & $43(93.5)^{3)}$ & $34(94.4)$ & $9(90.1)$ & \multirow{2}{*}{0.530} & $17(94.4)$ & $26(92.9)$ & \multirow{2}{*}{1.000} \\
\hline 11000 & $3(6.5)$ & $2(5.6)$ & $1(10.0)$ & & $1(5.6)$ & $2(7.1)$ & \\
\hline $\mathrm{DDS}^{2)}$ & $3.0 \pm 0.2^{4)}$ & $2.9 \pm 0.2$ & $2.9 \pm 0.3$ & 0.624 & $2.9 \pm 0.2$ & $2.9 \pm 0.3$ & 0.836 \\
\hline
\end{tabular}

${ }^{1)}$ grains, meat, vegetable, fruit, and dairy pattern, ${ }^{2)}$ dietary diversity score, ${ }^{3)} \mathrm{n}(\%),{ }^{4}$ Mean $\pm \mathrm{SD},{ }^{5)} \mathrm{p}$ value using Student's t-test or Fisher's exact test

Table 6. Amounts of Food Provided for each Food Group in the Meal Boxes (g)

\begin{tabular}{|c|c|c|c|c|c|c|c|c|}
\hline \multirow{2}{*}{ Food group } & \multirow{2}{*}{ Guideline $^{1)}$} & \multirow{2}{*}{ Total } & \multicolumn{3}{|c|}{ Meal type } & \multicolumn{3}{|c|}{ Price } \\
\cline { 4 - 9 } & & $\begin{array}{c}\text { Rice plus side dish } \\
(\mathrm{n}=36)\end{array}$ & $\begin{array}{c}\text { One-dish } \\
(\mathrm{n}=10)\end{array}$ & $\mathrm{P}^{8)}$ & $\begin{array}{c}<3,900 \\
(\mathrm{n}=18)\end{array}$ & $\begin{array}{c}\geq 3,900 \\
(\mathrm{n}=28)\end{array}$ & $\mathrm{p}$ \\
\hline Grain & $1.3(273 \mathrm{~g})^{2)}$ & $213.25 \pm 33.30^{7)}$ & $209.22 \pm 32.60$ & $227.78 \pm 33.38$ & 0.120 & $211.23 \pm 40.07$ & $214.55 \pm 28.87$ & 0.746 \\
\hline Meat & $3.3(198 \mathrm{~g})^{3)}$ & $135.52 \pm 46.02$ & $150.77 \pm 35.06$ & $80.59 \pm 39.03$ & $<0.001$ & $114.73 \pm 54.79$ & $148.88 \pm 34.15$ & 0.026 \\
\hline Vegetable & $2.7(189 \mathrm{~g})^{4)}$ & $68.44 \pm 36.06$ & $63.01 \pm 28.20$ & $87.99 \pm 53.52$ & 0.184 & $72.43 \pm 42.96$ & $65.87 \pm 31.42$ & 0.553 \\
\hline Fruit & $1(100 \mathrm{~g})^{5)}$ & $1.19 \pm 4.82$ & $0.82 \pm 3.55$ & $2.54 \pm 8.03$ & 0.524 & $1.41 \pm 5.99$ & $1.05 \pm 4.01$ & 0.809 \\
\hline Dairy product & $0.3(60 \mathrm{ml})^{6}$ & $0.12 \pm 0.81$ & 0.00 & $0.55 \pm 1.74$ & 0.343 & $0.31 \pm 1.30$ & 0.00 & 0.331 \\
\hline
\end{tabular}

${ }^{1)} 1 / 3$ of daily recommended servings for $19-29$ year-old Korean men, ${ }^{2)} 1$ serving for rice $=210 \mathrm{~g},{ }^{3)} 1$ serving for meat $=60 \mathrm{~g},{ }^{4)} 1$ serving for vegetable $=$ $70 \mathrm{~g},{ }^{5} 1$ serving for fruit $=100 \mathrm{~g},{ }^{6} 1$ serving for dairy product $=100 \mathrm{ml},{ }^{7)}$ mean $\pm \mathrm{SD},{ }^{8} \mathrm{p}$ value using Student's t-test

Table 7. Calorie and Nutrient Contents of the Meal Boxes

\begin{tabular}{|c|c|c|c|c|c|c|c|c|c|c|c|c|c|}
\hline \multirow{3}{*}{\begin{tabular}{|c|} 
Calorie and nutrient \\
Energy (kcal) \\
\end{tabular}} & \multirow{3}{*}{$\begin{array}{c}\text { Guideline }^{1)} \\
866.7\end{array}$} & \multirow{2}{*}{\multicolumn{2}{|c|}{$\begin{array}{c}\text { Total } \\
(\mathrm{n}=28)\end{array}$}} & \multicolumn{5}{|c|}{ Meal type } & \multicolumn{5}{|c|}{ Price } \\
\hline & & & & \multicolumn{2}{|c|}{$\begin{array}{l}\text { Rice plus side dish } \\
(\mathrm{n}=23)\end{array}$} & \multicolumn{2}{|c|}{$\begin{array}{c}\text { One-dish } \\
(\mathrm{n}=5)\end{array}$} & \multirow{2}{*}{$\frac{p^{4)}}{0.129}$} & \multicolumn{2}{|c|}{$\begin{array}{l}<3,900 \\
(\mathrm{n}=13)\end{array}$} & \multicolumn{2}{|c|}{$\begin{array}{l}\geq 3,900 \\
(\mathrm{n}=15)\end{array}$} & \multirow{2}{*}{$\begin{array}{c}\mathrm{p} \\
0.008\end{array}$} \\
\hline & & $7172 \pm 161.1^{2)}$ & $\left.82.8^{3}\right)$ & $737.6 \pm 1645$ & 85.1 & $644.9 \pm 131.5$ & 74.4 & & $639.6 \pm 144.7$ & 73.8 & $7722 \pm 1515$ & 89.1 & \\
\hline $\begin{array}{c}\text { Carbohydrate } \\
\text { (\% of total energy) }\end{array}$ & $55-65$ & $59.4 \pm 92$ & - & $58.5 \pm 9.8$ & - & $635 \pm 4.0$ & - & 0.160 & $62.1 \pm 9.6$ & - & $57.0 \pm 8.5$ & - & 0.030 \\
\hline $\begin{array}{c}\text { Fat } \\
\text { (\% of total energy) }\end{array}$ & $15-30$ & $30.6 \pm 9.0$ & - & $31.7 \pm 9.4$ & - & $25.4 \pm 42$ & - & 0.792 & $26.7 \pm 7.7$ & - & $34.0 \pm 89$ & - & 0.179 \\
\hline $\begin{array}{c}\text { Protein } \\
\text { (\% of total energy) }\end{array}$ & $7-20$ & $15.0 \pm 3.0$ & - & $14.9 \pm 3.0$ & - & $152 \pm 33$ & - & 0.129 & $15.8 \pm 3.0$ & - & $142 \pm 3.0$ & - & 0.008 \\
\hline $\begin{array}{c}\text { Sugar } \\
\text { (\% of total energy) }\end{array}$ & $10-20$ & $4.9 \pm 3.7$ & - & $5.1 \pm 39$ & & $4.0 \pm 23$ & - & 0557 & $4.4 \pm 4.5$ & - & $5.2 \pm 2.8$ & - & 0.561 \\
\hline $\begin{array}{l}\text { Saturated fatty acid } \\
\text { (\% of total energy) }\end{array}$ & $<7$ & $75 \pm 35$ & 107.6 & $79 \pm 3.8$ & 113.0 & $5.8 \pm 0.8$ & 83.0 & 0233 & $63 \pm 3.1$ & 89.6 & $8.6 \pm 3.6$ & 1232 & 0.076 \\
\hline Protein $(\mathrm{g})$ & 21.67 & $25.9 \pm 49$ & 119.7 & $26.0 \pm 5.1$ & 120.0 & $25.6 \pm 4.4$ & 118.1 & 0.872 & $245 \pm 49$ & 1129 & $272 \pm 4.7$ & 1255 & 0.144 \\
\hline Cholesterol (mg) & $<100$ & $114.6 \pm 54.6$ & 114.6 & $117.0 \pm 562$ & 117.0 & $103.6 \pm 50.6$ & 103.6 & 0.629 & $1035 \pm 53.6$ & 1035 & $1242 \pm 553$ & 1242 & 0325 \\
\hline Sodium (mg) & 500 & $1211.8 \pm 3784$ & 242.4 & $1,1624 \pm 374.6$ & 2325 & $1,439.0 \pm 340.8$ & 287.8 & 0.141 & $1,114.9 \pm 467.0$ & 223.0 & $1,295.7 \pm 270.1$ & 259.1 & 0.213 \\
\hline
\end{tabular}

${ }^{1)} 1 / 3$ of Estimated Energy Requirements or Recommended Intake of $19-29$ year-old men per day, ${ }^{2)}$ Mean $\pm \mathrm{SD},{ }^{3)} \%$ of guideline, ${ }^{4)} \mathrm{p}$ value using Student's t-test 
The average calorie content of the meal boxes was 717 $\mathrm{kcal}$, which was higher than the result found in a previous study investigating the nutritional value of eight convenience store meal boxes (643 kcal) [14]. Nevertheless, the average calorie content in this study did not satisfy one-third of daily estimated energy requirements for men aged from 19 to 29 years, corresponding to only $82.8 \%$. Regardless of the type and price, the calorie content was deficient as a single meal for young men and the meal boxes costing less were more likely to be deficient in calorie content. On the other hand, the more expensive meal boxes contained more fat and saturated fat, and the energy contribution of fat and saturated fat was relatively higher, exceeding the recommended level. This result could be because of the higher inclusion of fried food made of meat products. The excessive sodium content is also worthy of comment. The sodium content was almost 2.5 times more than the onethird daily adequate intake (AI) for Korean adults, and $60.5 \%$ of the WHO recommended daily intake of 2,000 $\mathrm{mg}$. The cholesterol content also needed reducing since it too was more than the daily recommended intake.

Consumers have evaluated the quality of meal boxes purchased from convenience stores lower than those sold in restaurants [10] and the satisfaction level with health and nutrition-related aspects of meal boxes has also been rated very low [11]. There is an urgent need to develop nutritionally balanced meal boxes. In Japan, the development of nutritionally balanced meal boxes has been progressed rapidly [23,24] For example, Lawson, a Japanese convenience store company, has developed a 3:1:2 meal box. The 3:1:2 method is a concept of nutritionally balanced meal, used as a known a nutrition education practice tool in Japan, in which the volume ratio of rice, main dish, and side dish is 3:1:2 [25].

A Korean traditional meal is a diet in which the intake ratio of meat and vegetables is balanced. The proportion of vegetable and animal food in a Korean traditional meal is about 8:2, which has been evaluated as a healthy eating pattern [26]. For healthy diets, there needs to be an increase in the proportion of vegetables, rather than too much meat, by using traditional method menus, and to develop menus based on the Korean traditional diet for convenience store meal boxes. In a previous study, a preference for vegetarian menus was ranked highest among the menu items desired for inclusion in convenience store meal boxes [18]. However, our study revealed that only about one-third of the meal boxes included namul and salad. Considering that consumers also pointed out that menu diversity in meal boxes is a problem to be improved [18], convenience store meal boxes need to adapt better and more varied cooking methods besides stir-frying or deep-frying.

Consumers of convenience store food are seeking as much information as possible about the quality of PB food, such as its nutritional value and safety [27]. It has also been found that consumers regard nutritional labeling as an important factor when purchasing meal replacements at convenience stores [28]. According to the current Food Hygiene Law, convenience foods, such as kimbap, sandwiches, and hamburgers, must be labeled with nutritional information. However, meal boxes, which are not classified as convenience food, are not legally obligated to provide nutritional information [13]. It is encouraging that 28 out of the 46 meal boxes under study did provide information about calories and eight other nutrients. However, considering the continuing increase in the sales of convenience store meal boxes, nutritional labeling of meal boxes should be mandatory to encourage healthier consumer eating habits. Given the positive effects of nutritional labeling [29,30], it is believed that the provision of nutritional information in meal boxes could help consumers choose healthier food. Voluntary efforts by the convenience store companies and governmental policy in support of this measure are important, considering that the main consumers of convenience store meal boxes mainly comprised people who did not eat regular and balanced meals $[8,16,17,18]$.

\section{Conclusions}

In summary, convenience store meal boxes had a high serving portion of meat compared to vegetables, regardless of the type and price. There was also a high portion of food that was stir-fried or deep-fried, requiring more use of oil. While there were a high number of different side dishes, the variety and diversity of foods were very low. The energy content was deficient for young men; however, the protein, saturated fat, cholesterol, and sodium content were excessive. Therefore, convenience store meal boxes need to be improved to provide proper nutrition as a single complete meal for Korean adults. In addition, the meal boxes costing more had a higher portion of meat and deep-fried food than the cheaper meal boxes, which could have a further negative impact on maintaining a properly balanced diet. Therefore, it is necessary to develop meal boxes that meet the nutritional needs of consumers who frequently use convenience stores. Furthermore, a menu development strategy differentiated according to sex, age group, and job characteristics is needed. Finally, a serving ratio of menu items that is appropriate for Korean convenience store meal boxes also needs to be developed.

There are some limitations in this study. Since only meal boxes that were sold within a certain time in four major convenience stores were selected for study, careful attention should be paid when generalizing based on the results of this study. In addition, as the quality of the meal boxes was evaluated mainly based on the composition of the menu and nutritional information provided on the packaging, further studies should be undertaken on the nutritional contents. Finally, since we excluded other types of meal replacements, such as gimbap, sandwiches, and hamburgers, further studies need to include all food products that are sold as meal replacements at convenience stores to examine whether they are adequate nutritionally as a single complete meal. Notwithstanding these limitations, the results of this study will be useful for the development of standards and menu items for nutritionally balanced convenience store meal boxes.

\section{Acknowledgements}

This work was supported by 2015 Research Fund of Myongji University. 


\section{Statement of Competing Interests}

All authors declare no conflict of interest.

\section{References}

[1] Lee, H., Chung, L., Yang, I, "Conceptualizing and prospecting for home meal replacement (HMR) in Korea by Delphi technique", Korean J Nutr, 38:251-258. 2015.

[2] 岩㴊道生, 外食産業論, 農林統計協会, 1996.

[3] Foodbank, The reasons of success of convenience store meal boxes. 2017/2/13 [cited 2017/5/10]; Available from: http://www.foodbank.co.kr/news/articleView.html?idxno=50900.

[4] Kirby, D.A, "Convenience stores", The polarisation of British retailing. Retail and Distribution Management, 14:7-12. 1986.

[5] Korea Chain Store Association, Distribution Enterprise Yearbook. Chain Store Association, Korea, 2016.

[6] Korea Association of Convenience Store Industry, The reasons of success of PB products in convenience stores. 2016/10/20 [cited 2017/5/10]; Available from: http://www.cvs.or.kr.

[7] Korea Association of Convenience Store Industry, The market of convenience store meal boxes. 2015/12/31 [cited 2017/5/10]. Available from: http:// www. cvs.or.kr.

[8] Embrain Trend Monitor, "Survey of meal box use of workers", Embrain Trend Monitor, 3:402-432. 2014.

[9] Jung, S, Use condition and satisfaction level for convenient food [master's thesis]. Seoul: Sungshin Women's University, 2001.

[10] Embrain Trend Monitor, "Survey of meal box use". Embrain Trend Monitor, 3:250-99. 2015.

[11] Park, S.J, A study on the status and policy issues that home meal replacement (HMR) industry in Korea, Korea Rural Economic Institute, Korea, 2015.

[12] Korea Association of Convenience Store Industry, Convenience store meal boxes with higher cost are in great demand. [cited 2017/5/10]; Available from: http://www.cvs.or.kr.

[13] Korea Ministry of Government Legislation, Food Sanitation Act. [cited 2017/5/10]; Available from: http://www.law.go.kr

[14] Korea Consumer Agency, Survey on safety management of meal boxes of convenience stores. KCA, Seoul, 2016.

[15] Choi, H., Kwon, S., Yoon, J, "Government-funded meal support program for low-income children through convenience stores: current status and nutritional quality of available meal items in Seoul", Korean J Community Nutr, 16:253-64. 2011.

[16] Jung, H.S, Consumer's purchasing behaviors in convenience stores [master's thesis], Seoul: Sookmyung Women's University; 1994.

[17] Yim, S.M, The use and awareness for convenience store's meal substitution food of adolescents in Seoul [master's thesis], Seoul: Kyunghee University; 2013.

[18] Embrain Trend Monitor. "Survey on use and awareness about meal box of convenience stores". Embrain Trend Monitor, 4:1-38. 2016.

[19] Yoon, S.S, Dictionary of Korean Food. Minumsa, Seoul, 1991.

[20] Kant, A.K., Schatzkin, A., Block, G., Ziegler, R.G., Nestle M, "Food group intake patterns and associated nutrient profiles of the US population", J Am Diet Assoc, 91:1532-1537. 1991.

[21] Ministry of Health and Welfare and the Korean Nutrition Society, Korean Dietary Reference Intakes 2015. Ministry of Health and Welfare and the Korean Nutrition Society, Seoul, 2016.

[22] Zhang Z.Y, Liu X.J, Hong X.Y, "Effects of home preparation on pesticide residues in cabbage", Food Control, 18:1484-1487. 2017

[23］小林弘幸, コンビニに「健康」を買いに行こう!. 主婦の友社, Tokyo, 2013.

[24] 長野県健康福祉部, 信州ACEプロジェクト取組方針及び実施 計画 (平成 27 年度), 2015/5/29 [cited 2017 February 10]; Available from: http://www.pref.nagano.lg.jp

[25] Adachi, M, "Theories of nutrition education and promotion in Japan: enactment of the Food Education Basic Law", Asia Pac J Clin Nutr, 17:180-184. 2008.

[26] Chung, H.J. Characteristics of Hansik, Komunsa, Seoul, 2010, 26-37.

[27] Ryu, M.H, "Undergraduate consumers' information needs according to purchase intention toward convenience store private brand foods", Fam Environ Res, 51:623-635. 2013.

[28] Kwon, S., Kim, O, "Consumer perceptions of nutrition labeling at fast-food restaurants in Seoul", J East Asian Soc Dietary Life, 24:544-551. 2014.

[29] Hersey, J.C, Wohlgenant, K.C, Arsenault, J.E, Kosa, K.M, Muth, MK, "Effects of front - of - package and shelf nutrition labeling systems on consumers", Nutr Rev, 71:1-14. 2013.

[30] Sinclair, S.E, Cooper, M, Mansfield, E.D, "The influence of menu labeling on calories selected or consumed: a systematic review and meta-analysis", J Acad Nutr Diet, 114:1375-1388. 2014. 